\title{
Invertebrate species inventories in protected area management: are they useful?
}

\author{
I. Engelbrecht ${ }^{1,2}$ \\ ${ }^{1}$ Directorate of Nature Conservation, Gauteng Department of Agriculture and Rural Development, Johannesburg, \\ 2000 South Africa.E-mail: ian.engelbrecht@gauteng.gov.za / adustus@ananzi.co.za \\ ${ }^{2}$ Research Associate, Department of Zoology and Entomology, University of Pretoria, Pretoria, 0002 South Africa
}

\begin{abstract}
Inventories of invertebrate species are produced by a number of workers for protected areas in South Africa. The value of these inventories for the protected area management process was investigated using a questionnaire to protected area managers, and by examining a sample of published inventories. The questionnaire results indicate that species inventories are sought after, but that they are largely not used in the management process. Invertebrate species inventories have the potential to be useful in several stages of the protected area management process, but making inventories useful requires more than a list of species names. To make inventories more useful they should include estimates of inventory completeness or statistically rigorous estimates of relative species richness, information on spatial distribution of species richness within a protected area, or their design should target threatened and rare species or aim to identify potential indicator species. Protected area managers and scientists producing inventories should collaborate to ensure that the resultant information is most useful.
\end{abstract}

Key words: invertebrate conservation, protected area management, species lists, checklists.

\section{INTRODUCTION}

Generating inventories of invertebrate species occurring on protected areas is a common activity undertaken by both citizen scientists and professional invertebrate biologists in South Africa. Inventories of species, often referred to as species lists or checklists, are usually the end result of opportunistic surveys targeting a chosen superspecific taxon. The inventory process serves a wide range of purposes, including obtaining specimens for taxonomic research, and providing educational opportunities for students and the general public. Importantly, they contribute to the knowledge base of the biodiversity represented within a protected area, and are seen as valuable information by both protected area managers and those generating inventories. Very often, the motivation for undertaking surveys on protected areas is that the resultant information will be useful in managing biodiversity in those protected areas.

Examples of uses of inventories in protected area management are presented by Droege et al. (1998) and Speight \& Castella (2001). Droege et al. (1998) showed how repeated inventories, such as bird lists generated by bird watchers visiting a protected area, may be used as a monitoring tool to determine how species composition in the protected area changes over time. If trends in species disappearance are detected, the cause of such disappearances can then be investigated and corrective action taken. Speight \& Catella (2001) showed that by linking regional inventories, data on species biology and protected area inventories, information on individual species biology may be linked and used in the interpretation of protected area inventories. If a species is known to occur in the region of the protected area, but is not recorded for the protected area itself and should occur there based on available habitat, then appropriate management interventions can be implemented to restore the habitat to a condition favourable for that species.

While these may appear as attractive uses of inventories, it is important not to underestimate the challenge of generating inventories of invertebrate species. Invertebrate communities often have significantly greater numbers of species than vertebrate animal assemblages, and sampling them relatively comprehensively requires substantial effort (Coddington et al. 2009). Inventory efforts are also often hampered by the difficulty in identifying many invertebrate species, the lack of easily available and user friendly identification tools, and the limited availability of taxon experts to assist in the identification process.

Given these challenges, the purpose of this article is to explore the assumption that inventories of invertebrate species are needed for effective 
management of biodiversity in protected areas. It presents the results of a questionnaire survey of protected area managers and ecologists to determine how species inventories are used in practice. It also investigates the prevalence of invertebrate research on protected areas that only generates inventories relative to other invertebrate research. The management planning process is described briefly and suggestions are provided for how the inventory process may be extended to be more beneficial to this process.

\section{METHODS}

A questionnaire, comprising 10 short questions, was developed to determine the perceived value and use of inventories in South African protected areas. The questions aimed to establish if an ecological management plan was in place for the protected area under consideration, whether there were specific management objectives or actions for invertebrates included in the plan, whether inventories of invertebrate species exist for the protected area, and whether these were used in developing management objectives and actions. It also requested information indicating the purposes for which invertebrate species inventories are otherwise used, and how such inventories may be improved to make them more useful in protected area management. Of the 10 questions, eight were closed type questions requiring specific, predefined answers. Place for comments was provided for some of these. The last two questions were open ended and requested suggestions on how inventories might be improved for the biodiversity management process or any other thoughts the responder had regarding invertebrate inventories.

The questionnaire was circulated electronically, with a covering letter explaining the purpose of the study and stating that individual responses would be kept confidential. These were sent to the relevant management staff in conservation agencies responsible for protected areas in each of the nine provinces, as well as SANParks, which is responsible for national protected areas. They were then distributed by these managers to protected area managers and regional ecologists reporting to them. Responses were voluntary, and provided directly to the author. The responses to the open ended questions and the comments provided with closed questions were categorized and the number of respondents making a particular suggestion were scored.

To determine the prevalence of research generating basic species inventories relative to other invertebrate research, three South African scientific journals, African Entomology, African Invertebrates and Koedoe, were searched for articles on invertebrates in protected areas. The former two are general entomological journals, while Koedoe includes articles on a range of research topics on protected areas in South Africa and neighbouring countries, and is published by South African National Parks. The key words 'reserve', 'park', 'protected area' and 'conservation' were used to locate relevant articles in African Entomology and African Invertebrates, while the complete contents of Koedoe were searched manually. The search was conducted for the years 2000 to 2009, inclusive. The resulting articles were classified as inventories, research other than just inventories, or a combination of both. If a list of species was the focus of the article then the article qualified as an inventory.

\section{RESULTS}

Thirty one responses to the questionnaire were received. The results of these are presented in Table 1.

The results of the literature search for research on invertebrates in protected areas were as follows. Sixteen articles were located in the three journals searched. Nine $(56 \%)$ of these were classified as inventories only (Dippenaar-Schoeman et al. 2009; Haddad \& Dippenaar-Schoeman 2009; Dippenaar et al. 2008; Haddad et al. 2006; DippenaarSchoeman 2006; Dippenaar-Schoeman et al. 2005; Haddad 2003; Dippenaar-Schoeman \& Leroy 2003; Foord et al. 2002), one (Wesolowska \& Haddad 2009) included an inventory as well as other research, in this case systematics of the taxon. Six comprised other kinds of research. Of the latter, Davis et al. (2005) examined representation and habitat requirements of dung beetles in protected areas in Gauteng province, DippenaarSchoeman \& González-Reyes (2006) indicated representation of solifuge species in South African protected areas, Esterhuizen (2006) discussed seasonal abundance of horse flies in two KwaZulu-Natal Nature Reserves, and de Kock \& Wolmarans (2008), Wolmarans \& de Kock (2006) and de Kock et al. (2002) examined the spread of alien aquatic molluscs, the impacts of extreme 
Table 1. Questions and response results for questionnaire circulated to protected area managers and regional ecologists.

No. Question

1 Are you a Reserve Manager, Regional Ecologist or other responsibility?

2 Does your protected area have an Ecological Management Plan as per the Protected Areas Act?

3 Are invertebrates specifically considered in any of the biodiversity management objectives in the

Ecological Management Plan, or in any other management planning documentation for your protected area? Please provide details

$4 \quad$ Do you have any inventories (i.e. species lists) for any invertebrate groups (e.g. beetles, butterflies, spiders, earthworms, etc.)

5 Do you feel that these inventories are an accurate representation of the species that occur in your protected area? Elaborate if necessary

6 Would you like to have inventories of more invertebrate groups for your protected area? Elaborate if necessary

7 Have you used these species lists in any way in developing your Ecological Management Plan or other management documentation for your protected area, or do you use these species lists in planning or implementation of your biodiversity management actions on your protected area?

If yes, please provide details

8 Do you use these species lists for any other purposes on your protected area (eg. providing information to tourists)? If yes, please elaborate.

9 \& Suggestions for improvement of inventories and 10 comments on inventories in general

Responses

Comments

Reserve Manager: $61 \%$

Regional Ecologist: $39 \%$

Yes: $61 \%$

No: $16 \%$

In preparation: $23 \%$

Yes: $42 \%$

№: $58 \%$

Yes: $58 \%$

No: $42 \%$

Yes: $17 \%$

No: $39 \%$

Unsure: $44 \%$

(Only scored for those who answered yes to previous question)

Yes: $97 \%$

Only one respondent indicated that he/she didn't wantinventories for the protected area)

(Of the 18 respondents who answered Yes to question 4, 15 responded to this question)

Yes:13\%

No: $87 \%$

(20 respondents answered this question) Yes: $55 \%$

No: $45 \%$

Stated indicators of ecosystem health or change would be useful: $26 \%$

Conservation status and management recommendations for rare/threatened species should be included: $19 \%$

Inventories should be more complete:

$13 \%$

Habitat requirements of species should be indicated: $6 \%$

All of the following suggestions were made by single respondents (3\%)

Data on spatial occurrence and abundance should be included.

Lists should include references to voucher specimens.

Alien species should be indicated.

Impacts of fire and herbivore management on invertebrate diversity should be researched
Examples included: Undertake baseline surveys, do projects on priority species, conservation of invertebrate species in general, monitoring of threatened species and biocontrol agents, control of locust population.

One example was provided stating that management actions had been formulated for a threatened species found on the protected area

Provided to tourists: $20 \%$

Available on website: $25 \%$

Provided to researchers: $10 \%$

Use as educational material: $5 \%$ 
climatic events on molluscs, and the status of molluscs in the Kruger National Park, respectively. Eight of the articles classified as inventories were published in Koedoe and all of these were produced as outputs from the South African National Survey of Arachnida (SANSA).

In searching the articles classified as inventories for statements of their value for protected area management, several were found to reflect the perception that effective management of biodiversity on protected areas requires a near complete knowledge of the invertebrate species present (Dippenaar-Schoeman et al. 2009; DippenaarSchoeman et al. 2005; Dippenaar-Schoeman \& Leroy 2003; Foord et al. 2002). One described inventories as a conservation planning tool and stated that the lack of such information is an impediment to effective conservation planning (Haddad \& Dippenaar-Schoeman 2009). This article also discussed the value of inventories as baseline information for monitoring of impacts of climate change, alien species and habitat transformation. Wesolowska \& Haddad (2009) indicated that invertebrates should be considered in the management plan for a protected area where species richness of the taxon studied was high, but did not provide specific recommendations on what this would require.

\section{DISCUSSION}

The key findings of the questionnaire survey with respect to the value of invertebrate inventories are as follows. While most protected area staff would like inventories for their protected area, these are seldom used in formulating management objectives or actions. They are used more often as baseline information on the protected area, indicating the species present, and are made available to the general public and visiting researchers. Importantly, most respondents felt that inventories were incomplete or were unsure as to their completeness. The predominant suggestions for improvement of the inventory process were to identify indicators of environmental change or ecosystem condition, and to identify species of conservation concern. Of the published research examined, approximately half consists of inventories only, with SANSA the primary producer of these inventory publications. These publications stated that inventories are important for conservation in protected areas and that invertebrates should be considered in protected area management, that inventories are a conservation planning tool and that they provide baseline information for monitoring.

Protected area management planning involves a progressive, iterative process, illustrated in Fig. 1. The stages of this process are information gathering, using the information gathered in formulating a vision and objectives for the protected area, identification of actions that will lead to achievement of those objectives, implementation of those actions, monitoring of the results of the actions for effectiveness, and changes to management actions if they are found to be ineffective (Thomas \& Middelton 2003). Management planning does not stop with the production of a plan, but includes implementation of management actions, evaluation of their effectiveness and changing them where necessary. This approach is required in the management of complex, dynamic systems where the outcomes of management actions are not always certain, and is termed adaptive management (Holling 1978; Johnson 1999).

The setting of objectives is a key step in this process. Objectives simultaneously need to reflect the purpose of the protected area and provide the standard for assessment of management effectiveness. Objectives need to specifically state desired outcomes, and those outcomes must be achievable, realistic and measurable. Objectives are usually set for biodiversity management, tourism and income generation, infrastructure development, education and training, and organizational capacity, amongst others. Biodiversity management objectives usually consist of statements of intention to maintain levels of biodiversity, populations of rare and threatened species, or the management of threats to biodiversity such as alien species or erosion.

Inventories might provide information that would be useful during four of the stages in the management process. First, they may provide information on the value of the protected area for biodiversity conservation. This may be in the form of an indication of absolute species richness within the protected area, richness relative to other protected areas, the number of species occurring in the region that are represented in the protected area, or the relative contribution of the protected area to a regional protected area network in representing the species occurring in the region. If inventories indicate high value in any of these 


\section{Uses of inventories}

\section{Protected area management planning}

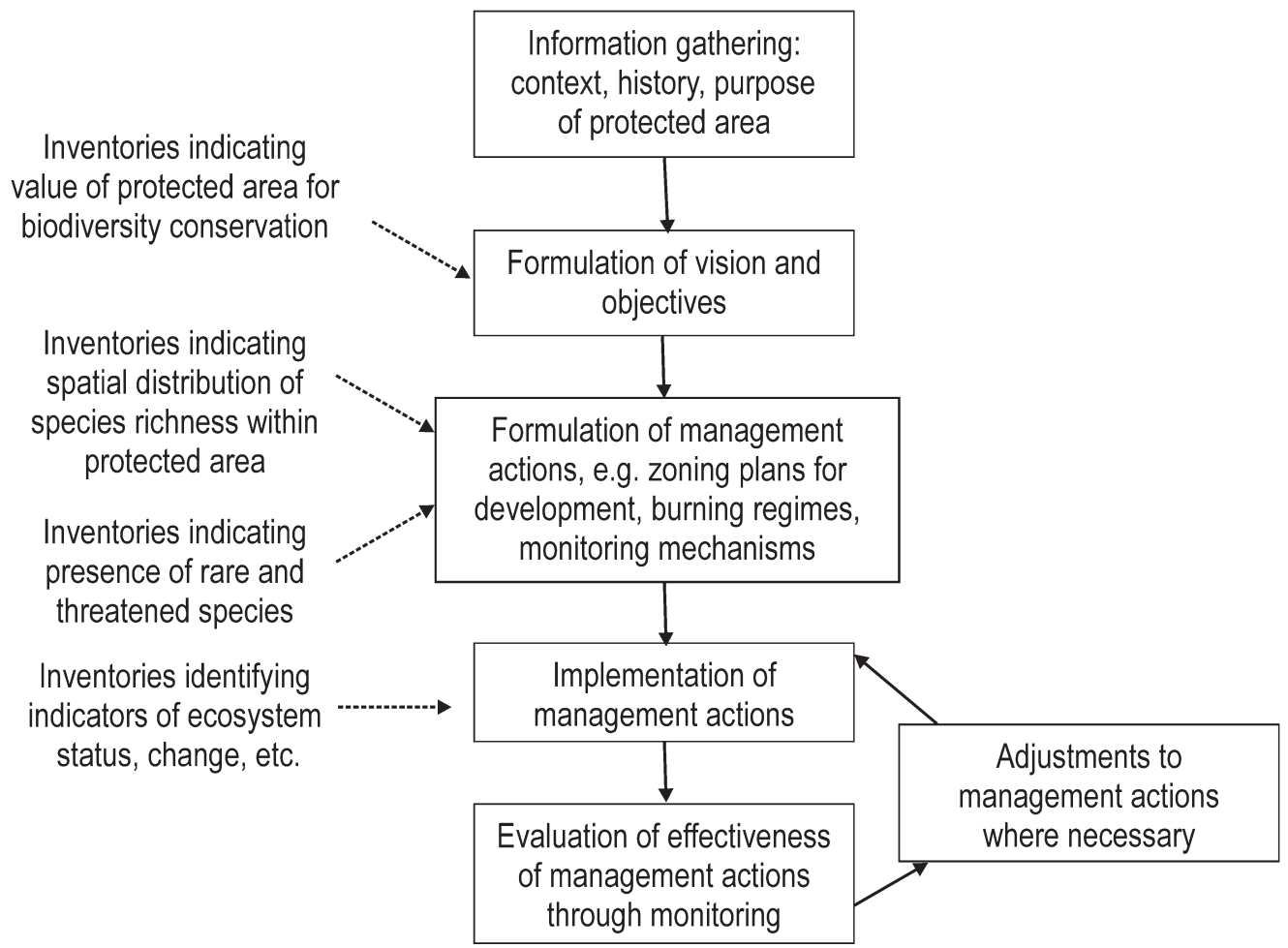

Fig. 1. The protected area management planning process indicating stages where invertebrate species inventories may be useful. Derived from Thomas \& Middleton (2003).

aspects, that information can be used to motivate for continued existence of the protected area and allocation of the necessary funds and resources to implement the management actions. Second, if the inventory process generates information on spatial patterns of species richness within a protected area, that information can be used in zoning the protected area for different uses and for infrastructure development planning. Uses that potentially impact on biodiversity, such as infrastructure developments or high tourist density areas, can be located in areas of lower species richness. De Mas et al. (2009) provide an example of how species richness of spiders was mapped for a protected area in Spain for this purpose. Third, information from inventories may be used in determining specific management actions. In particular, if rare or threatened species are located during the inventory process specific management actions can be formulated to maintain or improve habitats for those species, or to increase population sizes. Another example was provided by one of the questionnaire respondents, where a specific burning regime is implemented to maintain the habitat of a threatened butterfly species on the protected area. Lastly, inventories may provide information on the presence of species which may be used as indicators of management effectiveness which would be used at the stage of evaluating and refining management actions. Monitoring projects for evaluating management effectiveness are identified concurrently with the identification of management actions, and then implemented concurrently with or following the implementation of management actions. Haddad et al. (2009) provide an example where a spider species is determined to be an indicator of changes in forest structure due to elephant impacts.

The fact that the questionnaire respondents indicated that inventories are largely not used for these purposes would indicate that the information required to make inventories useful is not presented in the results of inventory projects, or 
that it is presented in a form that does not facilitate its use. These problems are addressed under the headings that follow, with suggestions on how the inventory process may be extended, sometimes very simply, to produce information that is relevant for management.

\section{Completeness of inventories}

In using inventories to justify the value of protected areas, completeness of the inventory is a key consideration. Protected area staff indicated uncertainty in the level of completeness of the inventories they have available. Invertebrate communities often have many more species than communities of vertebrates and plants and producing relatively complete inventories can be challenging. Coddington et al. (2009) reviewed a number of inventories of tropical arthropod communities and found that the proportion of singleton species averaged $32 \%$, indicating that most invertebrate communities are substantially undersampled. It is also characteristic of invertebrate community surveys to continue accumulating species with additional sampling effort, even after substantial sampling effort has been invested (see for example Novotn \& Basset 2000). Species richness estimation methods provide an indication of the degree of completeness of an inventory by extrapolating a curve of species accumulation relative to sample or specimen accumulation to an asymptote representing the likely number of species present (Gotelli \& Colwell 2001; Thompson et al. 2003; Chao 2005). The number of species observed relative to the estimate of total species present provides an indication of completeness of the inventory, as well as potential species richness for the area.

In comparing species richness between sampled areas it is also important to produce standardized estimates of richness relative to sampling effort (Gotelli \& Colwell 2001). Failing to do so can lead to tenuous conclusions about relative species richness, and hence the relative value of protected areas in conserving species. An example of such a comparison is presented in Dippenaar et al. (2008). They found 275 spider species in the protected area they surveyed and stated that this was comparable with the 268 species found in another protected area within the same biome, without comparing species accumulation curves. The sample for the first protected area included 13821 specimens while the sample from the second comprised 4832 specimens. Unless the species accumulation curve for the larger sample had reached an asymptote relatively early (which is unlikely for an invertebrate community), this would indicate a potentially greater species richness in the second protected area. Methods are also available for evaluating the similarity in species composition between different areas that consider missed species (Chao et al. 2005). These measures can be used to provide an indication of relative importance of individual protected areas in representing a regional fauna.

Species richness estimation methods may be applied to specific areas or habitats within a protected area in much the same way as they are applied to a protected area as a whole. De Mas et al. (2008) provide an example where spider species richness was correlated with environmental variables within a protected area, producing a species richness map for the total extent of the protected area. This is a good demonstration of how the inventory process can lead to valuable information for protected area management by using species richness estimation and predictive modelling methods.

Species richness estimation methods are freely available with software packages such as EstimateS (Colwell 2009) and richness estimates should be a minimum requirement of invertebrate inventories on protected areas. Not only will these give protected area staff a better indication of the level of completeness of inventories, but it would also allow for consideration of any uncertainty in applying the results of inventories in the management process.

\section{Inventories in identifying indicators and threatened species}

Several respondents indicated the need for information on indicators of environmental change and the presence of rare or threatened species on protected areas, and that the inventory process should aim to provide this information. This information is used in the management process by identifying management actions that benefit such species. However, generating such information is seldom the primary objective of inventory projects. This is problematic because both indicator identification and rare and threatened species detection require different approaches to those used for undertaking a basic inventory.

Developing indicators is arguably the more diffi- 
cult of these two activities. Indicator identification projects first require a specification of what it is that should be indicated. Some factors that might be of interest include changes in vegetation structure, the ratio of covered to bare ground or changes in species composition of plant or animal communities. These factors are usually related to management actions, such as burning regimes. The specific factors of interest would be identified during the information gathering and objectives setting stages of the management planning process for a particular protected area, and will vary from one protected area to another depending on the context and objectives of each. If the presence or absence of a particular species is strongly correlated with a factor of interest, this species is then an indicator of the factor. Identifying such correlative relationships is not trivial though. It requires that the sampling strategy be designed specifically to sample along gradients of the factor of interest and measures species responses to those gradients (Carignan \& Villard 2002; Duelli \& Obrist 2003). Inventory projects are often not designed in this way.

Determining the presence of rare or threatened species can also represent a challenge for the inventory process. Such species tend to be the most difficult to locate in a survey area due to their low abundance, specialized habitat requirements, localized distribution or cryptic behavior. General inventory projects may fail to locate these species for such reasons, and when they are located, it is often by chance. Detection of rare and threatened species would be more effective when those species are targeted using appropriate sampling methods (Thompson 2004; Guisan et al. 2006; Martikainen \& Kouki 2003). Targeting specific species during a survey is also more efficient as resources are not expended on collecting, sorting and identifying more common species. Such surveys should provide information on the spatial distribution of any rare or threatened species within the protected area so that this information may be considered in developing management actions for these species.

Sampling rare and threatened species also requires a prior knowledge of which species are rare and threatened. In South Africa, assessments of threat status have been conducted for dragonflies and damselflies (Odonata), butterflies, the stag beetle genus Colophon Gray 1832, millipedes of the genus Doratogonus Attems 1914, some crus- taceans such as river crabs and fairy shrimps, velvet worms (Onychophora), and some snails and slugs (IUCN 2009). Protected area managers should not expect an indication of species rarity or threat from inventories of invertebrate taxa where such assessments have not yet been conducted, and should be cautious if they are provided. This is because inferences of rarity and threat are often based on the prevalence of specimens in collections, or the personal experience of the collector, which may be subjective or biased. The discovery of new species during invertebrate inventory projects should be also treated as the norm and is a reflection of the status of the taxonomy of the invertebrate taxon as a whole rather than the biodiversity value of the protected area (Redak 2000).

\section{Inventories in conservation planning and as baseline information for monitoring}

Haddad \& Dippenaar-Schoeman (2009) discussed the value of inventories as a conservation planning tool and as baseline information for future research or monitoring. The authors' statement of the value of the inventory produced as a conservation planning tool is also somewhat vague as they don't indicate what they meant by the term 'conservation planning tool'. They may have been referring to the use of the inventory in the management planning process described above, as a systematic conservation planning tool, or in another activity that could fall under the broad concept of conservation planning. Protected area management planning and systematic conservation planning are both clearly defined processes with specific information requirements. Systematic conservation planning (Margules \& Pressey 2000; Pressey 2004) is the process of identifying areas required to meet a set of predefined spatial representation targets for threatened species, ecosystems and other biodiversity features. The results are used for protected area expansion and biodiversity stewardship programmes and in infrastructural and housing development planning. The information required for systematic conservation planning is spatially explicit data on the distribution of species richness, compositional similarity, rare and threatened species and spatial surrogates for ecological processes. It is not apparent how a single inventory is useful to this process from the discussion presented by the authors.

Using inventories as baseline information for 
future research and monitoring also requires some careful consideration, and depends on what is meant by the term baseline. Inventories can be useful in assisting in the process of specimen identification in future projects when the relevant taxonomic literature is fragmentary and well developed identification tools are not available. Here, inventories can be used in conjunction with a species catalogue to locate relevant literature containing species descriptions. In this case users must be cautious of misidentifications that may arise from using inventories in this way. Misidentifications may occur when the person identifying a specimen assumes it is a species recorded in the inventory when he or she is uncertain of the true identity. If incorrect or outdated identifications are present in the inventory these can be propagated to newly collected specimens in much the same manner. The ideal situation for invertebrate research is to have a well resolved taxonomy and easily accessible, user friendly identification tools for the taxon under consideration. Identifications are then done using these tools, and prior inventories are not necessary.

Using inventories as a baseline for monitoring can also be challenging, particularly for invertebrates where inventories often miss large numbers of species. Monitoring involves the detection of trends of interest to protected area managers, such as changes in species composition, and relating those to management actions or other factors, such as climatic conditions. Such trends need to be reported with an indication of statistical significance, which requires a sampling strategy with appropriate replication and sample size (Nielsen et al. 2009). This sampling strategy must be developed prior to and applied in the initial baseline inventory if it is to be useful in monitoring projects.

When describing the value of inventories, authors should be specific in relating the information in the inventory to these, or other conservation related activities and the information should be presented in an appropriate format for future use in such activities. By specifically describing how an inventory may be used protected area managers are more likely to make use of the results of the inventory in their management activities.

\section{Inventory publication and SANSA inventories}

An interesting result of the literature survey is the prevalence of inventory publications stemming from the SANSA project. An examination of the publications list for the SANSA project, available on the project website (ARC 2010) indicates that inventory publication is a primary objective of this project with inventories produced for a range of agro-ecosystems and natural areas as well as protected areas. The project has also made a substantial contribution to the systematics of the southern African arachnid fauna, and provides a platform for communication and collaboration amongst arachnologists working in the region (Dippenaar-Schoeman \& Creamer 2000). The SANSA approach could be used as a model for coordinating inventories and taxonomic research at a national scale for other invertebrate taxa, but cost and feasibility of such projects must always be considered. The value of the individual inventories generated for protected areas by SANSA can be improved by following the suggestions presented in this article.

While SANSA was the primary source of publications in the literature examined, the questionnaire results indicate a relatively high prevalence of inventories for the protected areas surveyed, and the author is aware of several that exist for the protected areas in Gauteng Province. This would indicate that many invertebrate species inventories for protected areas are not published. While publication does ensure public availability of inventory results, it does have shortcomings. Scientific publications may become quickly outdated as a result of subsequent survey projects where additional species are discovered or due to taxonomic name changes. Publishing inventories can also be difficult as editors aim to increase readership and citations of their journals by selecting those articles most likely to be read and cited (see Primack 2009). The results of inventory projects are more appropriately made available through specimen or observation databases. Such databases can represent a near real time picture of species inventory results using current taxonomy, and can represent much richer information than that which is commonly presented in species lists, such as qualifiers of identification certainty or georeference accuracy (Chapman 2005). Information can also be extracted from databases in the format most appropriate for the intended use with custom designed queries, and common analysis can be automated within database systems. Databases from different collections are easily integrated using freely available tools to provide a compre- 
hensive dataset of species distribution records, which makes these records useful for a number of purposes not possible with single inventories (Edwards et al. 2000; Graham et al. 2004; Soberón \& Peterson 2004). Those undertaking inventory projects should ensure that the data collected are included in such online resources so that they are easily available and to ensure that maximum value may be derived from them.

\section{CONCLUSION}

Inventories of invertebrate species have the potential to contribute to the management planning process for protected areas, but this requires the presentation of more than a list of species names. They may contribute to the initial information gathering process as an indication of the value of the area for biodiversity protection or its relative importance in a protected area network. This requires standardized measures of species richness that compensate for incomplete sampling of species assemblages. By extending this approach within the protected area species richness maps may be produced which can be used in zoning the protected area for different uses or development planning. Inventories may also provide information on the presence of rare or threatened species. Management actions that aim to ensure the persistence of populations of these species can then be developed. An indication of the spatial distribution of such species should be presented in the results of the survey. Importantly, the objective of sampling rare and threatened species is only valid where rarity and threat status have been formally assessed for the taxon to be sampled. The identification of indicators of environmental condition or

\section{REFERENCES}

ARC 2010. South African National Survey of Arachnida. Online at: http://www.arc.agric.za/home.asp?pid $=3272$ (accessed 29 January 2010).

CARIGNAN, V. \& VILLARD, M. 2002. Selecting indicator species to monitor ecological integrity: a review. Environmental Monitoring and Assessment 78: 45-61.

CHAO, A. 2005. Species richness estimation. In: Balakrishnan, N., Read, C.B. \& Vidakovic, B. (Eds) Encyclopedia of Statistical Sciences. 7909-7916. Wiley, New York.

CHAO, A., CHAZDON, R.L., COLWELL, R.K. \& SHEN, T. 2005. A new statistical approach for assessing similarity of species composition with incidence and abundance data. Ecology Letters 8: 148-159.

CHAPMAN, A.D. 2005. Principles of Data Quality, version management action effectiveness can also be done by extension of the basic inventory process, but this requires a carefully designed sampling strategy that targets gradients of the factors of interest.

Both scientists and protected area managers have the responsibility to make sure that research on protected areas is beneficial to the management of the protected area. For protected area managers this means communicating management objectives and actions, as well as research questions, to researchers. They should also specify the format for information that will be provided by researchers that will be of most use to them. Researchers should also take the initiative to engage with protected area managers in those areas where they wish to work in order to find out how their research may be used in the management process. They should obtain and read management plan documents to better understand the objectives, management actions, and information requirements in preparation for their surveys. By fostering collaborative relationships and ensuring that inventory type research contributes to the management of protected areas, both protected area managers and researchers will benefit in the long term.

\section{ACKNOWLEDGEMENTS}

I would like to thank the managers in various conservation agencies for distributing the questionnaire and all respondents who took the time to contribute; P. Duigan, D. Koen, G. Masterson, M. Correia and three anonymous referees who provided suggestions for improvements to the manuscript, and A. Mathie for proofreading the final draft.

1.0. Report for the Global Biodiversity Information Facility, Copenhagen.

CODDINGTON, J.A., AGNARSSON, I., MILLAR, J.A. KUNTNER, M. \& HORMIGA, G. 2009. Undersampling bias: the null hypothesis for singleton species in tropical arthropod surveys. Journal of Animal Ecology 78: 573-584.

COLWELL, R.K. 2009. EstimateS: Statistical estimation of species richness and shared species from samples. Version 8.2. User's Guide and application published at: http://purl.oclc.org/estimates

DAVIS, A.L.V., SCHOLTZ, C.H. \& DESCHODT, C. 2005. A dung beetle survey of selected Gauteng nature reserves: implications for conservation of the provincial scarabaeine fauna. African Entomology 13(1): 1-16. 
DE KOCK, K.N. \& WOLMARANS, C.T. 2008. Invasive alien freshwater snail species in the Kruger National Park, South Africa. Koedoe 50(1): 49-53.

DE KOCK, K.N., WOLMARANS, C.T. \& DU PREEZ, L.H. 2002. Freshwater mollusc diversity in the Kruger National Park: a comparison between a period of prolonged drought and a period of exceptionally high rainfall. Koedoe 45(2): 1-11.

DE MAS, E., CHUST, G., PRETUS, J.L. \& RIBERA, C. 2009. Spatial modeling of spider diversity: matters of scale. Biodiversity and Conservation 18: 1945-1962.

DIPPENAAR, S.M., DIPPENAAR-SCHOEMAN, A.S., MODIBA, M.A. \& KHOZA, T.T. 2008. A checklist of the spiders (Arachnida, Araneae) of the Polokwane Nature Reserve, Limpopo Province, South Africa. Koedoe 50(1):10-17.

DIPPENAAR-SCHOEMAN, A.S. 2006. New records of 43 spider species from the Mountain Zebra National Park, South Africa (Arachnida: Araneae). Koedoe 49(2): 23-28.

DIPPENAAR-SCHOEMAN, A. S. \& CREAMER, C. 2000. The South African National Survey of Arachnida. Plant Protection News 56: 11-12.

DIPPENAAR-SCHOEMAN, A.S. \& GONZÁLEZ-REYES, A.X. 2006. South African National Survey of Arachnida (SANSA): Solifugae (sun-spiders) of the national parks and reserves of South Africa (Arachnida, Solifugae). Koedoe 49(2): 29-38.

DIPPENAAR-SCHOEMAN, A.S. \& LEROY, A. 2003. A check list of the spiders of the Kruger National Park, South Africa (Arachnida: Araneae). Koedoe 46(1): 91-100.

DIPPENAAR-SCHOEMAN, A.S., VAN DEN BERG, A. \& PRENDINI, L. 2009. Spiders and Scorpions (Arachnida: Araneae, Scorpiones) of the Nylsvley Nature Reserve, South Africa. Koedoe 51(1) Art. \#161, 9 pages. DOI: 10.4102/koedoe.v51i1.161

DIPPENAAR-SCHOEMAN, A.S., VAN DER WALT, A. E., DE JAGER, M., LE ROUX, E. \& VAN DEN BERG, A. 2005. The Spiders of the Swartberg Nature Reserve in South Africa (Arachnida: Araneae). Koedoe 48(1): 77-86.

DROEGE, S., CYR, A. \& LARIVÉE, J. 1998. Checklists: an under-used tool for the inventory and monitoring of plants and animals. Conservation Biology 12(5): 1134-1138.

DUELLI, P. \& OBRIST, M.K. 2003. Biodiversity indicators: the choice of values and measures. Agriculture, Ecosystems and Environment 98: 87-98.

EDWARDS, L.J., LANE, M.A. \& NIELSEN, E.S 2000. Interoperability of biodiversity databases: biodiversity information on every desktop. Science 289(5488): 2312-2314.

ESTERHUIZEN, J. 2006. Seasonal abundance of horse flies (Diptera: Tabanidae) from two conservation areas in northeastern KwaZulu-Natal Province, South Africa. African Entomology 14(2): 395-397.

FOORD, S.H., DIPPENAAR SCHOEMAN, A.S. \& VAN DER MERWE, M.M. 2002. A check list of the spider fauna of the Western Soutpansberg, South Africa (Arachnida: Araneae). Koedoe 45(2): 35-43.

GOTELLI, N.J. \& COLWELL, R.K. 2001. Quantifying biodiversity: procedures and pitfalls in the measure- ment and comparison of species richness. Ecology Letters 4: 379-391.

GRAHAM, C.H., FERRIER, S., HUETTMAN, F., MORITZ, C. \& PETERSON, A.T. 2004. New developments in museum-based informatics and applications in biodiversity analysis. Trends in Ecology and Evolution 19(9): 497-503.

GUISAN, A., BROENNIMANN, O., ENGLER, R., VUST, M., YOCCOZ, N.G., LEHMANN, A. \& ZIMMERMANN, N.E. 2006. Using niche based models to improve the sampling of rare species. Conservation Biology 20(2): 501-511.

HADDAD, C.R. 2003. Fruit chafers (Coleoptera: Scarabaeidae: Cetoniini) of the Ndumo Game Reserve and Tembe Elephant Park, KwaZulu-Natal. African Entomology 11(1): 130-133.

HADDAD, C.R., DIPPENAAR SCHOEMAN, A.S. \& WESOLOWSKA, W. 2006. A checklist of the non-acarine arachnids (Chelicerata: Arachnida) of the Ndumo Game Reserve, Maputaland, South Africa. Koedoe 49(2): 1-22.

HADDAD, C.R. \& DIPPENAAR-SCHOEMAN, A.S. 2009. A checklist of the non-acarine arachnids (Chelicerata: Arachnida) of the De Hoop Nature Reserve, Western Cape Province, South Africa. Koedoe 51(1) Art. \#149, 9 pages. DOI: 10.4102/ koedoe.v51i1.149.

HADDAD, C. R., HONIBALL, A.S., DIPPENAARSCHOEMAN, A.S., SLOTOW, R. \& VAN RENSBERG, R.J. 2009. Spiders as potential indicators of elephantinduced habitat changes in endemic sand forest, Maputaland, South Africa. African Journal of Ecology. DOI: $10.1111 / j .1365-2028.2009 .01133 . x$

HOLLING, C.S. (Ed.) 1978. Adaptive Environmental Assessment and Management. John Wiley, New York, New York.

IUCN 2009. IUCN Red List of Threatened Species. Version 2009.2. Online at: www.iucnredlist.org (downloaded 26 February 2010).

JOHNSON, B.L. 1999. The role of adaptive management as an operational approach for resource management agencies. Conservation Ecology 3(2): 8. Online at: www.consecol.org/vol3/iss2/art8/

MARGULES, C.R. \& PRESSEY, R.L. 2000. Systematic conservation planning. Nature 405: 234-253.

MARTIKAINEN, P. \& KOUKI, J. 2003. Sampling the rarest: threatened beetles in boreal forest biodiversity inventories. Biodiversity and Conservation 12: 1815-1831.

NIELSEN, S. E., HAUGHLAND, D. L., BAYNE, E. \& SCHIECK, J. 2009. Capacity of large-scale, long-term biodiversity monitoring programmes to detect trends in species prevalence. Biodiversity and Conservation 18(11): 2961-2978.

NOVOTNÝ, V., \& BASSET, Y. 2000. Rare species in communities of tropical insect herbivores: pondering the mystery of singletons. Oikos 89: 564-572.

PRESSEY, R.L. 2004. Conservation planning and biodiversity: assembling the best data for the job. Conservation Biology 18(6): 1677-1681.

PRIMACK, R.B. 2009. Why did we reject your paper? Biological Conservation 142: 1559.

REDAK, R.A. 2000. Arthropods and multispecies habitat conservation plans: Are we missing something? Environmental Management 26 (suppl. 1): S97-S107. 
SPEIGHT, M.C.D. \& CASTELLA, E. 2001. An approach to interpretation of lists of insects using digitised biological information about the species. Journal of Insect Conservation 5: 131-139.

SOBERÓN, J. \& PETERSON, A.T. 2004. Biodiversity informatics: managing and applying primary biodiversity data. Philosophical Transactions of the Royal Society of London B 359: 689-698.

THOMAS, L. \& MIDDLETON, J. 2003. Guidelines for Management Planning of Protected Areas. IUCN Gland, Switzerland and Cambridge, U.K.

THOMPSON, W.L. (Ed.) 2004. Sampling Rare and Elusive Species: Concepts, Designs and Techniques for Estimating
Population Parameters. Island Press, Washington.

THOMPSON, G.G., WITHER, P.C., PIANKA, E.R. \& THOMPSON, S.A. 2003. Assessing biodiversity with species accumulation curves; inventories of small reptiles by pit-trapping in Western Australia. Austral Ecology 38: 361-383.

WESOLOWSKA, W. \& HADDAD, C.R. 2009. Jumping spiders (Araneae: Salticidae) of the Ndumo Game Reserve, Maputaland, South Africa. African Invertebrates 50(1): 13-103.

WOLMARANS, C.T. \& DE KOCK, K.N. 2006. The current status of freshwater molluscs in the Kruger National Park. Koedoe 49(2): 39-44. 